\title{
EARLY CAREER PROFESSIONALS ADJUSTING TO THE WORK AND LIFEWORLD OF THE UNITED NATIONS'
}

Linda Martina Mülli

"Large corporations are often formidable and mysterious to people outside them, like giants that populate the earth but can only be seen through their shadows."2 This is what Rosabeth Moss Kanter remarked in her book Men and Women of the Corporation and she continued as follows: "Corporations are often equally mysterious to the people inside, whose views can be limited and parochial because they rarely get a sense of the whole." 3 This sentence, I assume, still holds true - not only for corporations but also particularly for international organizations like the United Nations (UN) and its agencies.

In my research, I seek to shed light on this large international organization focusing especially on its employees. With a look behind the scenes, I aim to better understand the dynamics and work culture(s) in this rather closed-off terra incognita of the United Nations and the practices of men and women working there. ${ }^{4}$

\section{Newcomers to the United Nations - introduction}

This paper deals with the United Nations system ${ }^{5}$ as a work and lifeworld. It sets out to explore how early career professionals enter the international organization, how they cope with its hierarchical organizational culture and how they eventually adjust to the United Nations system as a work environment.

1 This paper is based on my SNSF funded research project (working title: "Rituals in an International Work Environment. An Anthropological Research on Cross-cultural Relations and Interactions in United Nations Affiliated Organizations in Geneva and Vienna").

2 Kanter, Rosabeth M.: Men and Women of the Corporation, New York 1977, p. 4.

3 Kanter, Men, p. 4.

4 Based on Clifford Geertz, I understand "culture" as a human-crated "web of significance". In consequence, being part of an organization means to (re-)create a specific work culture and organizational culture. Geertz, Clifford: The Interpretation of Cultures. Selected Essays by Clifford Geertz, New York 1973, p. 5.

5 Referring to the UN as a 'system' is based on its self-imposed term: “The UN system, also known unofficially as the 'UN family', is made up of the UN itself and many affiliated programmes, funds, and specialized agencies, all with their own membership, leadership, and budget. [...]”, cf. URL: http://www.un.org/en/sections/ about-un/funds-programmes-specialized-agencies-and-others/, accessed: 07.06.2017. 
With this contribution, I aim to present initial insights into my multi-sited research study (in the sense of George E. Marcus) ${ }^{6}$ about biographies and careers of early career professionals in the context of the two official UN headquarters located in Geneva, Switzerland, and Vienna, Austria. ${ }^{7}$ Taking the headquarters in two European cities as a starting point, I investigate the professional development of in UN parlance so-called entry-level professionals. I focus particularly on how these men and women, who are still at the beginning of their career as international civil servants, make use of their specific dispositions and capitals in the Bourdieusian sense. ${ }^{8}$ With this approach, I seek to understand how early career UN professionals establish themselves as international civil servants in the field of an extremely competitive work environment.

There has been research on the "cosmopolitan identity" of international civil servants, on UN employees seen as "elite cosmopolitans" 10 and on the identity building of UNHCR ${ }^{11}$ professionals who are presented as "une élite transnationale" 12 . In contrast to these studies, my investigation does not focus on international civil servants as a uniform group. More precisely, it sheds light on early career professionals seen as 'newcomers' to the United Nations system tracing their experiences, practices and socialization in the environment of two UN headquarters. Past experience has shown that newcomers and career changers tend to reflect upon implicit intra-corporate con-

6 Marcus, George E.: Ethnography in/of the World System: The Emergence of Multi-Sited Ethnography, in: Annual Review Anthropology 24 (1995), pp. 95-117.

7 In a historical aside, I would like to remark that the Palais des Nations in Geneva became headquarters of the United Nations in 1966 - after hosting the League of Nations in the first half of the $19^{\text {th }}$ century and long before Switzerland's admission to the United Nations in 2002. In this connection, it should be noted that Prof. Dr. Jacques Picard was a co-founder and member of the initiative committee "pour l'adhésion de la Suisse à l'Organisation des Nations Unies (ONU)". The initiative was accepted in March 2002 with $54,6 \%$ of votes. The Vienna International Center (VIC) was inaugurated in 1979 as a UN headquarters in the city of Vienna. Before, Vienna was hosting a few international organizations since the late 1950s.

8 Bourdieu, Pierre: The forms of capital, in: Richardson, John G. (Ed.): Handbook of Theory and Research for the Sociology of Education, New York 1986 [1983], pp. 246-258; Bourdieu, Pierre: Distinction. A Social Critique of the Judgment of Taste, Cambridge 1984 [1979].

9 Nowicka, Magdalena/Kaweh, Ramin: Looking at the Practice of UN Professionals: Strategies for Managing Differences and the Emergence of a Cosmopolitan Identity, in: Nowicka, Magdalena/Rovisco, Maria (Eds.): Cosmopolitanism in Practice, London/New York 2009, pp. 51-71; Nowicka, Magdalena: Transnational Professionals and their Cosmopolitan Universes, Frankfurt a. M. 2006.

10 Jansson, André: How to become an 'elite cosmopolitan': The mediatized trajectories of United Nations expatriates, in: European Journal of Cultural Studies 19/5 (2016), pp. 465-480.

11 United Nations High Commissioner for Refugees.

12 Fresia, Marion : Une élite transnationale: la fabrique d'une identité professionnelle chez les fonctionnaires du Haut Commissariat des Nations Unies aux Réfugiés, in: Revenue Européenne des Migrations Internationales 25/3 (2009), pp. 167-190. 
ditions. ${ }^{13}$ This is also what I noted during my stay in the field of research. Compared to their senior colleagues early career professionals are generally more open in sharing their views and experiences made in the field of international organizations. It seems that they do not yet feel entirely part of the new work environment. They recently joined the organization and it may take months, if not years, to familiarize with the new work environment. When not yet feeling part of the new organization and its culture, the comparison of the current situation with experiences, views and ideals a newcomer had prior to joining the United Nations comes more easily to his/her mind. This also applies to former professionals who already left the organizational context and who are no longer affected by inner-organizational regulations and obligations.

In what follows, I will first provide a brief insight into my research project and the data collection. I will reflect on what it means to conduct ethnographic research in the context of international organizations. This includes an introduction to the discussion on studying up research situations in general. In particular, I will present a short reflection on the chosen research approach for this study. In the second part, I will proceed with the explanation of the different staff categories that are relevant for my research. I will also outline two career entries for early career professionals, namely two socalled Entry-Level Hiring Programmes, which might lead to a position as international civil servant. Regularly, these ideal career entries and career paths are described and promoted at 'career fairs' targeting university graduates and young professionals. Hence, in the third section of this paper, I will present impressions collected during a field trip to a career fair. By doing this, I aim to illustrate how normative career concepts are promoted outside the context of international organizations. To put it more precisely, career fairs are places where graduate students and early career professionals, who aspire to work in the market of international cooperation, discover and eventually start internalizing the normative modes of behavior of this particular field. Against this background, I will exemplify the alternative 'third career path' - the individual, self-initiated and self-made career path into the United Nations system. It is characterized by precarious and short-termed employment contracts (internships and consultancies) and is explainable with promoted patterns of conduct and thought. In this context, capitals (in the sense of Pierre Bourdieu) become essential in order to successfully compete against peers. In supposing that the employees' convergence towards the UN system continues, once he/she is part of the UN staff, and further

13 Götz, Irene: Empirische Erhebungen in Industriebetrieben und bürokratischen Organisationen, in: Göttsch, Silke/Lehmann Albrecht (Eds.): Methoden der Volkskunde. Positionen, Quellen, Arbeitsweisen der Europäischen Ethnologie, Berlin 22007, pp. 249-269, here p. 258. 
assuming that the process of adjustment supports the employees' way to cope with the UN system including its requirements and policies, I will forth introduce Pierre Bourdieu's notion of illusio $^{14}$ in this specific field of labor. The concept of illusio means the interest in field-specific values and sense-making thereof as well as the adjustment to a field-specific habitus. The illusio shows and guarantees the employees' commitment to the UN system - and reflects the patterns of conduct and thought as already seen in the context of career fairs. With the example of e-learning courses accessible via the UN System Staff College's virtual campus, I will show how the United Nations' 'corporate identity' is enhanced and (re)produced. ${ }^{15}$

At the current state of my research, I argue that the process of adjustment to the United Nations system - the predisposition and ability to see this bureaucratic 'giant' at least partially in full light - is ambiguous and demanding. It challenges the newcomers to the system - even if many of my self-aware informants present their experiences as success stories. In this paper, I will exemplify the ambivalence of the United Nations system as a work and lifeworld by contrasting my informants' narrations with the 'corporate identity' as promoted in career fairs and in e-learning courses. In this connection, the interconnection of illusio and 'corporate identity' will be discussed and the possible use thereof for the international organization. Additionally, another question arises, namely whether there exists a field-specific habitus that could be framed as, what I call it, habitus of international life and work.

\section{Studying up in international organizations}

According to Marc Abélès the anthropologists' interest in "nouveaux lieux de pouvoir"16 such as international organizations, is a logical outcome of the discipline's recent history. This includes the strong research interest in organizational anthropology ${ }^{17}$, labor anthropology $y^{18}$ and anthropology of policy ${ }^{19}$ - fields of research that have been com-

14 Bourdieu, Pierre: Homo Academicus, Cambridge 1988 [1984], p. 56

15 Notably, human resources departments of each UN body offer particular workshops to build the corporate culture.

16 Abélès, Marc (Ed.): Des anthropologues à l'OMC. Scènes de la gouvernance mondiale, Paris 2011, pp. 15-31, here p.19.

17 Garsten Christina/Nyqvist, Anette (Eds.): Organisational Anthropology. Doing Ethnography in and among Complex Organisations, London 2013.

18 Götz, Irene: Sensing Post-Fordist Work Life. Recent Perspectives in the Ethnography of Work, in: Ethnologia Europea 41/1 (2013), pp. 68-87.

19 Shore, Cris/Wright, Susan (Eds.): Anthropology of policy. Critical Perspectives on Governance and Power, London/New York 1997. 
monly investigated by other disciplines. Abélès further stresses the importance of qualitative research methods, such as participant observation during a considerable period of time, when it comes to research in the context of international organizations.

Being a young academic aiming to research work conditions in a venerable and powerful institution like the United Nations automatically means to be confronted with studying up research situations - a term coined by Laura Nader. ${ }^{20}$ In view of the democratic relevance of anthropological research, Nader pointed out several decades ago that we as cultural and social anthropologists "have specialized in understanding whole cultures in a cross-cultural context. We should, for example, be at home in studying the law firm as a secret society, in finding and analyzing the networks of power $[\ldots]$ ". ${ }^{21}$ Nader stressed the importance to open up new fields of research that might appear like "secret societies", such as in this case study the United Nations. Recent studies adopt this approach emphasizing the need that anthropologists shall meet with both their research field and their informants on equal footing. ${ }^{22}$

Unlike Abélès and his fellow researchers, I did not opt for a top down research approach supported by a leading figure on the top of the organizational hierarchy. In contrast, I followed Cris Shore's research strategy and chose a bottom up research approach when I was working as an intern in two UN agencies headquartered in Vienna. ${ }^{23}$ The bottom up approach enabled me to get into a field of research, which is extremely difficult to access. ${ }^{24}$ Like Marion Fresia, I was, on the one hand, part of the staff and involved in daily project work activities. ${ }^{25}$ On the other hand, I was a researcher doing ethnographic fieldwork, writing down my observations and reflections in my field diary. Thus, for approximately thirteen months I was able to experience and observe the work and lifeworld of the UN headquarters in Vienna, called Vienna Inter-

20 Nader, Laura: Up the Anthropologist. Perspectives Gained from Studying Up, in: Hymes, Dell (Ed.): Reinventing Anthropology, New York 1972, pp. 284-311.

21 Nader, Anthropologist, p. 293 [italics in original].

22 Von Dobeneck, Florian/Zinn-Thomas, Sabine: Statusunterschiede im Forschungsprozess, in: Leimgruber, Walter et al. (Eds.): Methoden der Kulturanthropologie, Bern 2014, pp. 86-100; Wright, Susan/Reinhold, Sue: 'Studying through'. A Strategy for Studying Political Transformation. Or Sex, Lies and British Politics, in: Shore, Cris et al. (Eds.): Policy Worlds. Anthropology and the Analysis of Contemporary Power, New York 2011, pp. 86-105.

23 Shore, Chris: European Integration in Anthropological Perspective. Studying the 'Culture' of the EU Civil Service, in: Rhodes, R. A. W et al. (Eds.): Observing Government Elites. Up Close and Personal, Basingstoke 2007, pp. 180-205, here p. 180.

24 I am fully aware of the ethical questions that arise in consequence of my quasi-investigative research approach. Detailed discussions on this issue, however, transcend the purpose of this paper.

25 Fresia, Marion: Building Consensus within UNHCR's Executive Committee. Global Refuge Norms in the Making, in: Journal of Refugee Studies 27/4 (2014), pp. 514-533, here pp. 516-517. 
national Center (VIC), from an 'inside' and an 'outside' perspective. In this connection, David Mosse suggests the notion of insider ethnography. ${ }^{26}$ In this sense, for me as a researcher coming from, what in UN terms is called 'the outside context' into the ethnographic field of the VIC, it meant to always have this double role as an intern and 'inside ethnographer'.

In the light of this, it should be noted that not only ethnographic researchers use this spatial and contextual distinction. My informants use the same terms; they say "inside" when referring to the United Nations context and "outside" when talking about everything not belonging to the area of international organization. This again shows the imagined but also the actually real separation of the United Nations system from the outside world and the importance to take a look inside large international organizations.

Being on-site and cooperating with my colleagues and direct supervisors - whom I have informed about my academic interest - enabled me to collect preliminary ethnographic data through participant observation. I attended meetings and official events, I was engaged in more informal situations like lunch and coffee breaks, and I participated in diverse leisure activities such as joint excursions and staff parties - before finally starting with audio-recorded semi-structured interviews. In the currently eleven interviews conducted, I posed my informants open questions regarding their biographical and professional background, I asked them to tell me about their current private and professional situation, about their 'role' as international civil servants, and more. For this research study, I primarily interviewed early career professionals whom I met during my stay in the field, via the so-called 'snow-ball effect' through persons I had already interviewed or via social media, the latter applies only to a small number of my interviewees due to the lacking relationship of trust. At the time of the interview they were between 27 and 39 years old and only have spent a few years within the United Nations system, particularly in the headquarters in Geneva and Vienna. The interviews lasted between 45 minutes and three hours. With two exceptions, the interviews did not take place in the working context, but during my informants' spare time. Conducting the interviews outside the working context allowed long and open conversations of trust between the interviewee and the interviewer.

26 Mosse, David: Anti-social anthropology? Objectivity, objection, and the ethnography of public policy and professional communities, in: Journal of the Royal Anthropological Institute (N.S.) 12 (2007), pp. 935-956, here p. 936. 


\section{The United Nations workforce and career entries into international organizations}

According to the international organization's official website, which provides information on occupational careers within the United Nations system, "[ $t]$ he United Nations workforce is made up of different categories of staff. Within each category there are different levels, which reflect increasing levels of responsibilities and requirements." 27 In total, there are five different major job categories for UN staff members. Being assigned in one of these categories means to enjoy several privileges, such as having access to the UN social security system, receiving financial support for spouses and children, benefitting from tax exemption and more.

The categories vary in the process of recruitment (international vs. local), in required relevant work experience as well as the required level of education and skills (tertiary education vs. high school certificate) - and consequently in hierarchy. In theory, the categories also include specific tasks and responsibilities (project management vs. administrative tasks). However, and this was also stressed by Marion Fresia, the division of labor among project managers (professional staff) and administrative assistants (general staff) can be and actually is constantly re-negotiated in daily work activities. ${ }^{28}$ The boundaries between specific tasks and responsibilities become blurry, also due to the job rotation policy, which for professional staff holds a compulsory job rotation. ${ }^{29}$ As a consequence, administrative assistants, who are not affected by the job rotation policy and usually keep their positions for several years or even for decades, are more familiar with bureaucratic operations of a specific United Nations organization. This means that the administrative assistants often undertake also their supervisors' tasks and are actively involved in project management. ${ }^{30}$ The latter - professional staff - usually take a while to familiarize with the characteristics and processes in their new employer organization, the United Nations. Furthermore, it should be noted that, due to the job rotation policy and the limited term employment contracts, professional staff is continuously concerned with the continuation of their career after the

27 Careers.un.org, Staff categories: https://careers.un.org/lbw/home.aspx?viewtype=SC (08.07.2016).

28 Fresia, Marion: Une élite transnationale: la fabrique d'une identité professionnelle chez les fonctionnaires du Haut Commissariat des Nations Unies aux Réfugiés, in: Revenue Européenne des Migrations Internationales 25/3 (2009), pp. 167-190, here p. 169.

29 The last reformation of the UN staff mobility policy (staff selection and managed mobility framework) was implemented in 2016 based on the General Assembly's adoption of the redefined mobility framework (A/ RES/68/265) in April 2014.

30 Interview with informant G, 23 May 2016. 
expiration of appointment - in UN terms called "separation from service". According to a mid-career professional, with whom I talked about this issue, he as a project manager needed the first two years of his seven-year contract for familiarization, "now I am really productive for three years - before looking for the next job". ${ }^{31}$

In my research, I focus on professional and higher categories - commonly known as professional staff or "P-staff" - and particularly on entry-level professionals (P1-P3) working in one of the two United Nations headquarters in Geneva and Vienna. These entry-level positions require an advanced university degree or a minimum of two or a maximum of five years of relevant working experience. ${ }^{32}$ Moreover, the profile of candidates for entry-level positions should respond to the fact that "[...]work in the professional category generally demands a high degree of analytical and communication skills, substantive expertise and/or managerial leadership ability". ${ }^{33}$ Daily work tasks comprise of problem analysis and evaluation as well as "decision-making involving discretionary choices between alternative courses of action".

In other words, the highly skilled men and women employed in professional and higher categories are knowledge-workers belonging to a knowledge society. ${ }^{34}$ By job description, they must aim to constantly improve their skills and level of knowledge "through other training, self-study, or practical experience". ${ }^{35}$ This implies not only a subtle demand and pressure for constant self-optimization. It also implicates that employees in the United Nations system regularly complete basic and advanced training. Moreover, some of my informants are taking postgraduate program alongside work or are even working on a doctoral thesis. Hence, especially among early career professionals there is an ongoing competition that becomes even more essential when faced with fixed-term contracts of employment, due to the strict adherence to personnel rotation.

In addition, a general willingness to prove one's strong commitment to hard work, to self-optimization and, by this, becoming a legitimate member of the United Nations system, are further reflected in the description of the recruitment examinations. These UN Entry-Level Hiring Programmes, seen as "a platform for launching a career" ${ }^{36}$ at the

31 Field note, 29 April 2014.

32 UN career aspirants with no or little work experience apply via a competitive recruitment examination, as outlined below.

33 Careers.un.org, Staff categories: https://careers.un.org/lbw/home.aspx?viewtype=SC (08.07.2016), applies also to the next quote in this paragraph.

34 Beck, Ulrich: The Brave New World of Work, Oxford 2000 [1999]; Koch, Gertraud/Warneken, Bernd J. (Eds.): Wissensarbeit und Arbeitswissen. Zur Ethnographie des kognitiven Kapitalismus, Frankfurt a. M. 2012.

Careers.un.org, Staff categories: https://careers.un.org/lbw/home.aspx?viewtype=SC (08.07.2016).

Unis.unvienna.org, YPP - the Road to your UN Career: http://www.unis.unvienna.org/unis/en/events/2012/ ypp-seminar-2012.html (08.07. 2016). 
United Nations Secretariat, offer positions for the short period of one to two years. They are open to early career professionals with little or no work experience - commonly unpaid UN internships are not recognized as such - who originate from a socalled un- and under-represented country. ${ }^{37} \mathrm{~A}$ second requirement for participation is to be fluent in either of the official UN languages (English or French). Third, in the year of the examination, the candidates must be younger than 32 years of age.

On one hand, there is the Young Professionals Programme (YPP). This UN recruitment examination addresses "talented, highly qualified professionals" 38 across the world. Once yearly, the international organization launches a call for applications. There are recruitment exams for specific "job families" - "depending on projected needs of the United Nations", as quoted from the official website. ${ }^{39}$ For instance, the call in 2015 included exams for the following job categories: Administration, Finance, Legal Affairs, Public Information and Social Affairs and Statistics. According to the UN Secretariat, this recruitment examination is highly popular. In average, 40.000 applicants take the exam every year. ${ }^{40}$ To return to the example of the already completed YPP examination cycle of 2015, only 104 candidates successfully passed the twostage examination procedure - including a 4,5-hour hand written exam followed by a personal interview. ${ }^{41}$ However, passing the YPP examination does not guarantee a UN position. A rule stipulates that "[...] successful candidates are put on the reserve list to fill available job positions every three months". ${ }^{2}$ The names of the successful candidates will remain on "reserve list" for two years. ${ }^{43}$ Afterwards, the candidates' names on the roster will be deleted and they have to take the exam again. In view of the high competition and considering the fact that YPP exams remain extremely difficult, candidates who are not fully familiar with the United Nations system face difficulties to pass the exam. ${ }^{44}$ To illustrate this, a candidate who successfully passed the YPP exam in 2011 explains how she, thanks to diligence and persuasion, managed to pass the

37 The continuously adapted list of un- and under-represented countries reflects the geographical representation among the UN workforce. Countries form the 'global North' are usually overrepresented.

38 Careers.un.org, Young Professionals Programme: https://careers.un.org/lbw/home.aspx?viewtype=NCE\&lang=en-US (08.08.2016).

39 Careers.un.org (08.08.2016), applies also for the source in the subsequent phrase.

40 Humanrightscareers.com, UN Entry-Level Hiring Programmes: http://www.humanrightscareers.com/ un-entry-level-hiring-programmes/ (09.01.2017).

41 Careers.un.org (08.08.2016).

42 Humanrightscareers.com, UN Entry-Level Hiring Programmes: https://careers.un.org/lbw/home.aspx?viewtype $=$ NCE\&lang $=$ en-US $(08.07 .2016)$.

43 Careers.un.org (08.08.2016).

44 Field note, Informal talk with a candidate of the YPP examination, Vienna, December 2015. 
preparation period - "a relentless marathon (supported by surreal amounts of coffee... )." ${ }^{45}$ Notably, this person has been full time employed as a general staff during the preparation period and exam. During my stay at the headquarters in Vienna, I experienced that this double workload seems quite normal. This attitude reflects the normative career concepts that will be outlined in the subsequent section of this paper.

On the other hand, the United Nations Associate Experts Programme offers vacancies for so-called Junior Professional Officers (JPO). These positions are sponsored by the governments of specific partner countries and are therefore restricted to candidates with the respective nationality or to candidates from low- and middle-income countries. Currently, there are approximately two dozen donor countries financing JPO positions. Usually, JPOs receive an initial employment contract for the period of one year. In many cases, they then are responsible for the third-party funding that would guarantee the prolongation of their appointment in the second year of employment.

Both career opportunities are described in detail on the United Nations organizations' websites and advertised in official videos or interviews. In a short video, for instance, which was published in 2015 and is accessible via social media, the interviewed persons talk about their "journey around the world". 46 The interviewees presented as "motivated young people" admit that they "wanted to become part of the UN" ever since they were children or young adults. Furthermore, we learn from the interviewed JPOs that "[they] are adventurous, passionate, [...] committed, openminded". The interviewees state that they finally would be engaged in "real work" and that they would "feel really privileged to work in an organization like the UN". Similar statements I also heard during my internships in the UN headquarters in Vienna. ${ }^{47}$

\section{With capitals on the "many roads to Timbuktu"}

The normative requirement to be committed, dedicated, highly motivated and talented I kept hearing at the career fair in Berne, Switzerland, titled "A journey in international cooperation". 48 At that day in late October 2016, more than 1000 participants

45 Unis.unvienna.org, The YPP Road: http://www.unis.unvienna.org/pdf/2012/YPP/The_YPP_Road_Szilvia-Petkov.pdf (20.12.2016).

46 Undp.org, The JPO programme - A JPO journey around the world: http://www.undp.org/content/jposc/en/ home/how-to-join/the-jpo-programme.html (20.12.2016), applies also to the quotes in the next two sentences.

47 Field note, Informal talk with young female consultant, VIC, 27 April 2015.

48 The Forum cinfo 2016 "A journey in international cooperation" was organized by the cinfo foundation, funded in 1990 by the Swiss Agency for Development and Cooperation (SDC). 
wanted to learn more about how to best start this "journey" in order to become an international civil servant. HR recruiter from several UN organizations and other international bodies dedicated to international cooperation explained the "many roads to Timbuktu" 49 , as it was promoted in the opening session. The message was clear: Career aspirants must belong to the most convincing candidates who would ensure "securing the highest standards of efficiency, competence and integrity" 50 as stipulated in the UN Charter. The emphasis on commitment, hard work and the 'mantra' saying that the lengthy and precarious lean period of unpaid internships and short-termed consultancy contracts one day will pay off, were repeated regularly. ${ }^{51}$

In that response, it should also be noted that several participants raised their voices to rebut the image of a comfortable and carefree life as an early career professional. That is to say, they experienced what the majority of my informants experienced before becoming an entry-level professional. That is what I describe as the 'third career path' towards the United Nations system. This third individual, self-initiated and self-made entry option means to climb up the 'career ladder' by first completing unpaid internships - which can lead to quite precarious life circumstances, particularly in the expensive cities of Geneva and Vienna. ${ }^{52}$ In any case, unpaid internships are only accessible to those who get third-party funds or loans, who receive financial support from their families or who were able to save money themselves. Eventually, the former interns are contracted as consultants. Again, they find themselves in a flexible situation, with shortterm contracts comprising of daily to monthly employment and no social security at all.

This third option best illustrates the flexible work regimes of the New Economy. ${ }^{53}$ In The Corrosion of Character Richard Sennett stressed the following: "In the flexible regime, the difficulties crystallize in a particular act, the act of risk-taking." ${ }^{54}$ Precisely, this implies that only career aspirants who can afford an (unpaid) internship and are able to take a risk when signing a short-term consultancy contract have the resources to pursue this 'third career path'.

49 Field note, Career fair Berne, 30 October 2016.

50 Charter of the United Nations, Chapter XV: The Secretariat (Article 101.3).

51 I assume that process of socialization already starts in educational institutions offering study programs that respond to the job market of international cooperation and international policy making. One example focusing on the European Union is Kerstin Poehls' study about cultural practices in the Collège d'Europe. Poehls, Kerstin: Europa backstage. Expertenwissen, Habitus und kulturelle Codes im Machtfeld der EU (Reihe Kultur und soziale Praxis), Bielefeld 2009.

52 Naturally, this includes also other duty stations.

53 Cf. Sennett, Richard: The Culture of the New Capitalism, New Haven/London 2006.

54 Sennett, Richard: The Corrosion of Character. The Personal Consequences of Work in the New Capitalism, New York 1998, p. 75. 
Being aware of these precarious working conditions, many early career professionals - including the majority of my informants - still opt for this 'third career path'. The self-initiated option seems to be more reasonable or even possible in view of the aforementioned recruitment examinations where candidates compete with applicants from across the globe. Furthermore, and as the collected data in the context of the headquarters in Geneva and Vienna show, for many early career professionals to work in an international organization is the only option - especially when lacking local language skills. The "journey around the world" turns into a migration biography and the early career professionals can be described and understood as highly skilled migrants who aim to stay where their partners, families and friends live. ${ }^{55}$

When aiming to 'climb the career ladder', capitals in the Bourdieusian sense are highly relevant. ${ }^{56}$ Before entering the United Nations system, objectified and institutionalized cultural capital ${ }^{57}$, in form of a prestigious university degree or voluntary work in the area of international cooperation, enhances chances to be invited for a job interview. Also, social capital ${ }^{58}$ in form of a key person who would help to arrange an internship or communities and other networks can be crucial when applying for an internship. Both, objectified cultural capital ${ }^{59}$ and social capital, enhance the applicant's 'visibility' in the vast number of applicants. ${ }^{60}$ Notably, the latter also increases a former intern's chances to be appointed as a consultant and, later on, eventually even as an entry-level professional. In addition, several of my informants mentioned the high importance of a mentor, in other words, a person in a senior position, who would not only provide support and guidance but particularly a network with other professionals. The latter, in turn, might be potential supervisors to the early career professional. Incidentally, the human resources management of the United Nations system also officially supports mentoring: "Mentoring provides career support and facilitates the transfer of knowledge and organizational culture." ${ }^{11}$ According to the official wording, mentoring is promoted as an ideal manner to enhance the career of junior professionals (mentees). In turn, the mentees would provide feedback to senior staff who, by being a mentor, would have the opportunity to train their leadership skills. For the organization, mentoring is

\footnotetext{
55 The detailed discussion of this research aspect would go beyond the scope of this article.

56 Bourdieu, Forms, pp. 46-58; Bourdieu, Distinction.

57 Bourdieu: Forms, p. 50.

58 Bourdieu: Forms, pp. 51-53.

59 Bourdieu: Forms, p. 50.

60 Field note, Informal talk with an HR recruiter, 21 October 2014.

61 HR.un.org, https: //hr.un.org/page/mentoring (20.12.2016).
} 
not only beneficial for the knowledge transfer; it even seems to subserve the preservation of a specific organizational culture.

Hand in hand with the social capital, the incorporated cultural capital helps to understand 'how to behave' and 'how to interact' in an international bureaucratic and quasi-diplomatic work environment. Once within the United Nations system, language skills enhance the ability to communicate and underline the individual's match with the international field. One episode, a dialogue between one of my informants and a superior staff member, underpins the value of symbolic capital ${ }^{62}$ : "He, a P-5, asked me: 'Can I tell you something about your shirts? They look cheap.' - 'They are cheap.' - 'Okay, but you have to [buy fine quality shirts]. Your image is important.' [...] I understood that he was trying to give me, what he perceived to be a good advice. [...] There is also an expectation of you -. And again, this is not written anywhere, but it's funny because the mission and the objective of the UN is not that. But the culture around the organization is like in any other organization and then you have to adapt to it [...]." ${ }^{33}$ My informant took the advice of the superior staff person to heart - admitting that he has to adapt to the organizational culture even if, to his mind, the people working in international cooperations should be concerned with more important issues than an elegant appearance. This scene illustrates the economic capital ${ }^{64}$, which not only bridges the financial bottleneck during unpaid internships and interruption between consultancy contracts but also allows to purchase symbolically important objects like expensive clothes - that would consolidate the image of being a serious professional.

In this connection, it ought to be mentioned that the (entry) salaries, which are, compared to the economic realities in the vast majority of United Nations member states, fairly high, enable to accumulate economic capital. Particularly in view of longterm careers in the United Nations system, the accumulated capital enables to bridge financial insecurities. Many of my informants tell me that they would safe a considerable amount of their income. One informant, who holds a P3 contract and who's chances to pursue a UN career in the middle and long term future, stated that the high salaries are justified, especially in view of the insecurity and due to the fact that the majority of employees in professionals and higher categories are geographically far away from their countries of origin and their local social security structures, family and community networks.

62 Bourdieu, Forms, p. 56.

63 Interview with informant E, 22 May 2016.

64 Bourdieu, Forms, p. 47. 
Finally, it is important to stress that other external assets such as citizenships and visas influence the individual ability to pursue the 'third career path'. More precisely, a European citizenship or a relevant visa facilitates or enables interns and consultants to stay in the respective city - after the termination of their employment contract and in search of a new one. I assume that this is one of the reasons for the overrepresentation of certain nationalities among international civil servants.

\section{More than a job: "It's a calling."}

After a long debate, the UN System Staff College was funded in 2001. Its main seat is located in Turin, Italy, and there is a second campus in Bonn, Germany. Furthermore, international civil servants can access the staff college's virtual campus that offers a large range of e-learning courses.

The former UN Secretary General, Ban Ki-moon, stated: "Joining the United Nations isn't just a job, it's a calling." ${ }^{65}$ This quote is repeated in the UN System Staff College e-learning course "Welcome to the UN: New Staff Orientation". In this virtual course designed to enhance the United Nations' 'corporate identity', participants are asked to choose between various "missions". These course sessions are titled "our organizational culture", "standards of conduct", "career development" and "conditions of service" - just to name a few examples.

Assuming, a participant starts with the first option, the following question pops up: "What motivated you to seek employment to the United Nations?" After answering the question, the participant is asked to compare his/her own motivation with other answers. The "motivation of others" appear in a virtual note book, on the opposite page of the participant's answers. Then, a female voice comments: "You'll quickly find out that there are many rewarding reasons to be part of the United Nations!" Indeed, the others' answers include not only the motivation "to improve the lives of others", but also "to learn about different cultures and points of view" as well as "to work in different parts of the world". In the interviews that follow, staff members talk about "the privilege and honor" to work for the United Nations. Mentioning the wish for social security, status, prestige and privileges would be inappropriate.

65 un.unssc.org, Welcome to the UN Family!, http://w2un.unssc.org/index.php (20.12.2016), applies also to the following quotes in this section. 
It seems that the UN System Staff College, "a distinct, system-wide, knowledge management and learning institution" ${ }^{\prime 6}$, makes use of the illusio - the participants' interest, commitment and willingness to embrace particular sense-making ideas and modes of behavior as well as to play along with the other actors in the field, in brief, the strong belief that participating in the game one day will pay off. ${ }^{67}$ The illusio builds upon the international organization's branding that includes prestige, honor and status. The aforementioned normative modes of behavior and mental states, which are presented on official websites and career fairs and where graduate students and early career professionals first learn about the social mechanisms and norms, again appear in the e-learning courses of the staff college. Employees take and accept the normative concepts, they respond to them and (re-)construct them further.

The interrelation between illusio and the construction of a specific UN 'corporate culture' reminds of Arlie Hochschild's notion of emotional labor. ${ }^{68}$ In The Managed Heart she analyzed how in a capitalistic context emotions are commercially exploited. As Hochschild puts it, the individual emotions replaced by institutional mechanisms: "The locus of acting, of emotion management, moves up to the level of the institution". 69

In similar vein, the illusio, actually (re)produced by the international civil servants, is instrumentalized on a macro-institutional level. As shown in the following quote, the illusio bridges moments of (financial) insecurity, pressure and stress - especially when employees' positions are not permanent but financed through third-party funds. One of my informants told me: "Because of the financial squeeze your empathy for the organization and your team increases. You put so much energy in because you want it the project, the team, the organization] to survive." ${ }^{\prime 0}$ Because employees believe in their "mission" and they truly identify with the above-mentioned aim to "improve the lives of others", they are willing to work hard - even when the project's continuation and, connected to it, their own future within the United Nations system are not guaranteed at all. It is therefore entirely plausible that a strong illusio serves the United Nations not only in view of the organization's social and cultural cohesion but also with regard to economic dimensions. This is particularly relevant for early career professionals on shortterm contracts, yet also for UN professionals affected by the staff rotation policy.

66 Unssc.org, History, http://www.unssc.org/about-unssc/history/ (20.12.2016).

67 Bourdieu, Homo, p. 56.; Cf.: Fröhlich, Gerhard/Rehbein, Boike: Bourdieu Handbuch. Leben - Werk - Wirkung, Stuttgart/Weimar 2014, pp. 129-130.

68 Hochschild, Arlie R.: The Managed Heart. Commercialization of the Human Feeling. Berkeley/Los Angeles/ London 1983, p. 7.

69 Hochschild, Heart, p. 49.

70 Interview with informant L, 22 December 2016. 
The illusio - the 'UN ideology' - is in such a strong manner embracing and powerful that many interns and consultants, who - even after a long period of trying to become an entry-level professional - do not succeed to establish themselves as international civil servants, are terribly ashamed and depressed. ${ }^{71}$ They perceive their dropout as a personal failure.

\section{From illusio to 'corporate identity' - conclusion and outlook}

In this paper, I first provided a short insight into the discussion on studying up research situations and I problematized this issue with a focus on the research approach chosen for this empirical study, namely when conducting field work in the two United Nations headquarters in Geneva and in Vienna. Second, I outlined various entry points and career paths open to early career professionals who aspire to become a what in UN terms is called professional staff member, more precisely entry-level professional. I described the logics of so-called Entry-Level Hiring Programmes, namely the Young Professionals Programme and the assignment as a Junior Professional Officer (JPO) in the United Nations Associate Experts Programme. I showed that capitals in the Bourdieusian sense are, on one hand, crucial when entering the 'giant' of the United Nations via the above-mentioned official hiring examination programmes. On the other hand and as shown in the third section of this paper, capitals become essential when pursuing an alternative, individual, self-made, yet often precarious career path via (unpaid) internships and short-contracted consultancies. Generally, capitals are crucial when pursuing a career as an international civil servant in the long run. Being lucky and finding a mentor - in the proper sense the unofficial relationship based on the mutual sympathy between mentor and mentee - means enhancing one's professional and social network, shortly, the social capital. Interestingly, the Human Resources management officially introduced mentoring as a concept according though which both, junior professionals and senior staff members, would benefit. Moreover, it would not only guarantee the knowledge transfer but also subserve the preservation of the organizational culture. Evidentially, cultural capital is key during the whole career as a knowledge worker leading projects in international cooperation and policy-making. Notably, economic capital is essential to stay on site, particularly in moments of a financial bottleneck when being 'separated' from the United Nations system when looking for a

71 One informant needed several months to overcome this, as she perceived it, personal failure. Cf. Interview with informant G, 23 May 2016. 
possible future employment contract. ${ }^{72}$ Fourth, I described how the normative modes of behavior and mental states are promoted in career fairs addressing career aspirants who aim to work the international cooperation. It is where social mechanisms and norms circulate, a phenomenon that can be associated with Bourdieu's notion of illusio. ${ }^{73}$ I showed how the UN System Staff College, an institution dedicated to enhance the 'corporate identity' of the United Nations system, makes use of the illusio promoting the correct modes of motivation. Workshops and e-learning courses serve to guarantee the continuing reproduction of the illusio. The illusio 'recycled' by the organization itself to create a 'corporate culture' serves the international organization also in economic dimensions. It motivates UN employees to perform committed work and deliver maximum performance - even in unsecure financial situations or future continuation of a particular unit, department or even organization. Given the financial difficulties of the United Nations, more and more positions seem to be financed with third-party funds.

As an outlook, it therefore would be interesting to investigate the future development of the interrelation between illusio and 'corporate identity' and compare it to its historical dimension. As shown in this paper, to pursue a UN career is difficult and competitive. As a final remark, I wish to raise the question whether early career professionals who have successfully entered the United Nations system, on a long-term perspective, develop an inner stance that goes beyond a strong identification with the United Nations as a work and lifeworld and that I might be framed in what I call habitus of international life and work. This habitus-alike identity of entry-level professionals enables to successfully pursue a career as an international civil servant. This, in contrast, would mean that those career aspirants who drop out probably did not embrace the illusio of the United Nations. Additionally, they perhaps also did not develop a habitus that would enable the final socialization and long-term professional integration into the United Nations system. This, of course, is only part of the explanation why some junior professionals succeed in becoming international civil servants and others not. But it might explain why some of these men and women are more "stubborn" 74 or "ambitious"75 or as some of my informants describe themselves.

72 In the jargon of the United Nations system, the termination of an employment contract is called "separation from service".

73 Bourdieu, Homo, p. 56.

74 Interview with informant E, 22 May 2016.

75 Interview with informant A, 27 April 2016. 